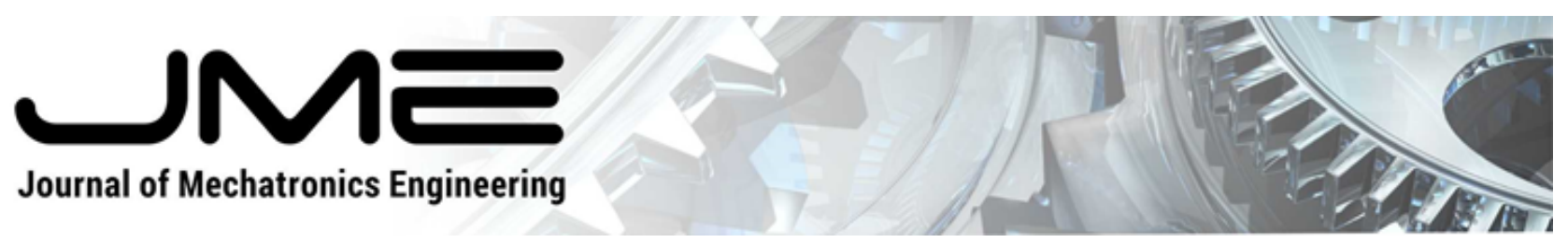

\title{
Investigation of internal flow of Cryogenic injection
}

\author{
Claus Franz WehmanN ${ }^{1}$, Marcello Reis $^{2}$, Meng LoU $^{3}$, OSKar Josef Haidn $^{3}$ \\ ${ }^{1}$ Federal University of Ceará - UFC, Brazil; ${ }^{2}$ Meteora Aceleradora, Brazil; \\ ${ }^{3}$ Technische Universität München, Germany \\ <claus.wehmann@ufc.br>,<mcarv.reis@gmail.com>, \\ $<$ luomeng1213@hotmail.com>,<oskar.haidn@tum.de>
}

DOI: http://dx.doi.org/10.21439/jme.v3i2.84

Received: 02 July 2020. Accepted: 09 Oct. 2020

\begin{abstract}
As part of an effort to understand the conditions for the ignition of cryogenic propellants in the low pressure environment, we conducted a research of internal flow of cryogenic jet. In this paper, the experimental investigation was exerted focusing on the qualitative morphology study of the cryogenic flow inside the jet injectors. The test facilities were carefully designed and allow for visualization and characterization of the flow. The results show a strong dependence of mass flow rate on the fluid temperature. The two-phase flow was observed even for a long time chilling down of the injector. The Jacob number is proved to be a good indicator for the flow regimes, and the bubbles are present in the flow every time. The injector geometry has an influence on the flow rate, with the tapered injector demonstrating a higher flow rate than the sharp one.
\end{abstract}

Keywords: Internal flow, Cryogenic fluid, Injection, Chill down.

\section{Nomenclature}

$\begin{aligned} \mathrm{A} & =\text { area of injector orifice } \\ C_{p l} & =\text { liquid heat capacity } \\ \mathrm{d} & =\text { injector diameter } \\ \dot{M} & =\text { mass flow rate } \\ p_{i n j} & =\text { injection pressure } \\ p_{a m b} & =\text { ambient pressure } \\ \Delta \mathrm{p} & =\text { drop pressure } \\ T_{s} & =\text { saturation temperature } \\ \rho & =\text { density } \\ \mu & =\text { viscosity }\end{aligned}$

\section{Introduction}

In the last decade, plenty of research have been conducted about the cryogenic injection with the operation conditions from near vacuum to higher than the critical pressure. Atomization of a cryogenic liquid is dominated not only by aerodynamic forces outside and turbulence inside the liquid jet, but also by thermodynamic effects of the fluid. This creates a multiphase flow or even an undistinguished fluid (not gas, not liquid) behavior and may dominate the atomization process. Effects of pressure and aerodynamic forces on the cryogenic injection have been studied intensively, while less work was contributed to exploring the impact of thermodynamic effect on the injection, i.e. flashing phenomena, the conditions of the internal flow (mainly for cryogenics fluids) are rarely covered, although their importance is well-known.

The research in atomization, mainly in liquid propellant rocket engines, has dealt with the problems of behavior of cryogenic fluids at critical pressures conditions (BRANAM; TELAAR; MAYER, 2001, MAYER, 1994, OSCHWALD et al., 2006; MAYER; TAMURA. 1996, CHEHROUDI; COHN; TALLEY, 2002). Under such pressure conditions, classical models of atomization are not applicable anymore.

Another subject of studies are the fluid behavior before the ignition (GAUTAM, 2007). At the upper-stage rocket engine, due to the low pressure environment, 
Investigation of internal flow of Cryogenic injection

the cryogenic liquid jet atomization is not driven by forces of aerodynamic nature (SHER; BAR-KOHANY; RASHKOVAN, 2008). Instead, the atomization is now controlled by thermal phenomenon inside the fluid. The release of a pressurized, superheated liquid into such environment results in violent nucleation, expansion and breakup of the liquid phase (CLEARY; BOWEN; WITLOX, 2007; VU; AGUILAR, 2009; YILDIZ et al. 2002), as so called flashing. Nevertheless, bubble formation and expansion as well as flashing even may happen inside the injector tube.

The characteristic of fluid itself that goes through injectors need to be better understood. Lin and Reitz (1998) draw attention to the need for considering the internal flow behavior. Other authors studied the effect of flow regime and injector geometry and were able to classify different types of cavitation (PAYRI et al. 2011; SOU et al., 2008, SOU; HOSOKAWA; TOMIYAMA, 2009; De Giorgi; FICARELLA; TARANTINO, 2013; BADOCK et al., 1999). The change of phase in a pipe due to heat transfer (named: chill-down) again is initiated prior to the injector (SHAEFFER; HU; CHUNG, 2013, RAMÉ; HARTWIG; MCQUILLEN 2014), Generally, in particular for cryogenic fluids, the flow across the injector, in some extent may be twophasic and thus it interfere with a classical atomization process.

Through careful design of the experimental setup, including the optical accessible injector with different geometrical design, optical chamber, cryogenic fuel feed system and measurement systems, the study aims at identification and characterization of dominating fluid-dynamic conditions, which evolve inside of injector. Particularly, the effect of different internal injector geometries on the flow and flashing phenomenon is studied. The work focus on the internal geometry and the formation of two-phase flow inside injectors.

\section{Theory}

The main variables related to that the inner injection study are the dimensionless flow rate and its dependencies with the pressure coefficient and temperature.

$$
\bar{M}=\frac{\dot{M}}{\frac{1}{4} \pi d^{2(2 \rho \Delta p)^{\left(\frac{1}{2}\right)}}}
$$

where: $\bar{M}$ the dimensionless flow rate, $\dot{M}$ mass flow rate, $d$ injector diameter, $\rho$ density and $\Delta p$ drop pressure.

Temperature is also dimensionless

$$
\theta=\frac{T_{i n j}}{T_{s}}
$$

where: $\theta$ dimensionless temperature, $T_{i n j}$ injection temperature and $T_{s}$ saturation temperature.

and the pressure coefficient

$$
C_{p}=\frac{P_{i n j}-P_{a m b}}{1 / 2 \rho_{l i q} v^{2}}
$$

where: $C_{p}$ pressure coefficient, $P_{i n j}$ injection pressure, $P_{a m b}$ ambient pressure and $\rho_{l i q}$ liquid density.

and the velocity is calculated by

$$
v=\frac{\dot{M}}{\rho_{l i q} A}
$$

where: $v$ velocity, $\dot{M}$ mass flow rate, $\rho_{l i q}$ liquid density and $A$ area of injector orifice.

Considering that we are dealing with a probable two-phase flow, the Jacob number is also calculated.

$$
J a=\frac{C_{p l} \times \Delta T \times \rho_{l}}{h_{l g} \times \rho_{g}}
$$

where: $J a$ Jacob number, $C_{p l}$ liquid heat capacity, $\Delta T$ drop temperature, $\rho_{l}$ liquid densty, $h_{l g}$ latent heat of vaporization and $\rho_{g}$ gases density.

Where $\Delta T$ is the difference between actual temperature and the saturation temperature $\left(\Delta T=T-T_{s}\right)$, and hlg is the latent heat of vaporization. From these data, we expect to learn about the effect of superheating and depressurization on this internal flow.

\section{Experimental set up}

\subsection{Test facilities}

The experimental setup (Fig. 1) consists of Liquid Nitrogen tank pressurized by a gas bottle, connected to an injector case and this one to a vacuum tank. There are three temperature measurement points. One in top of $L N_{2}$ tank, the second in the pre-chamber of injector and the last one in the vacuum chamber. Temperatures in the injector were obtained by thermocouples (copper-constantan, $\Phi 0.5 \mathrm{~mm}$ ). Pressure measurements was took in the same positions. The pressure is recorded with two pressure sensors (PMT-DS19, 0 16bar) in the tank and in the injector pre-chamber and one pressure sensor (Wika A-10, 0 1bar)in the vacuum tank, to get the pressure difference between the injection pressure and the chamber pressure. 
Investigation of internal flow of Cryogenic injection
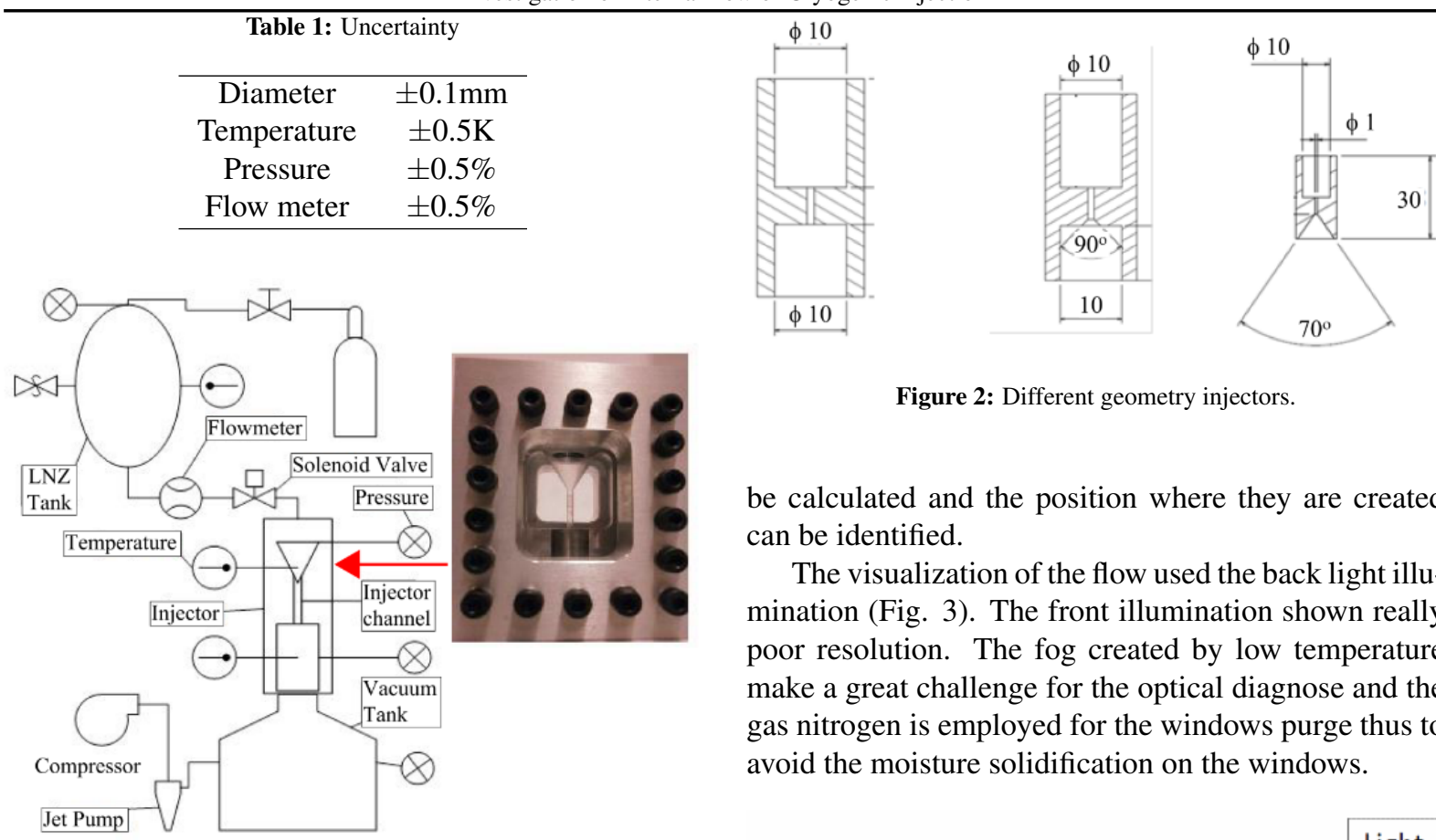

Figure 2: Different geometry injectors.

be calculated and the position where they are created can be identified.

The visualization of the flow used the back light illumination (Fig. 3). The front illumination shown really poor resolution. The fog created by low temperature make a great challenge for the optical diagnose and the gas nitrogen is employed for the windows purge thus to avoid the moisture solidification on the windows.

Figure 1: Injector set up.

With this measurement, it is possible to calculate the mass flow rate considering the flow as continuous liquid and then compared with the mass flow rate measured. The mass flow rate was recorded with a turbine flow meter NT/FT4-8(0.38 11L/min) Series.

\subsection{Injectors}

We tested 3 injectors (Fig. 2) with different geometries (injector 1: sharp entrance, injector 2: tapered entrance, injector 3: complete conical). Each injector has an orifice diameter of $1 \mathrm{~mm}$ and with the length to diameter ratio $\mathrm{L} / \mathrm{D}$ of 6 . The material (Acrilic) is very soft, and enables a tolerance of $\pm 0.1 \mathrm{~mm}$ for each dimension. they are encapsulated in an aluminum case (Fig. 1). The pressure and temperature before the injection and in the spray just half centimeter after injector mouth are shown in the sketch in the Fig. 1 .

\subsection{Optical measurement}

The flow phenomena inside these injectors were captured with a high speed camera (Photron Fastcam SA$\mathrm{X} 2$ ) using shadowgraphs technique. With the images of the high speed camera the average size of bubbles can

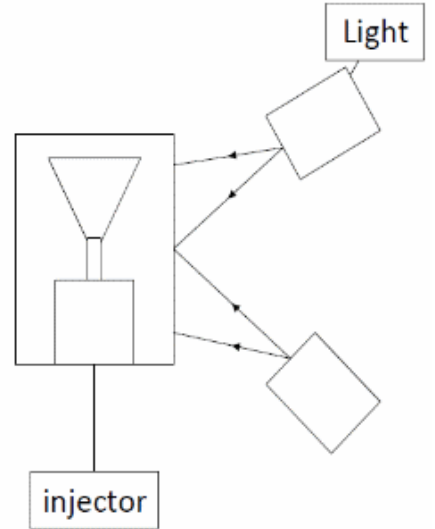

Figure 3: Optical set up.

\subsection{Test operation condition and process}

Each test campaign began with the evacuation of the pipe and tank by use of the vacuum pump. This procedure was taken because of the moisture in the air, that usually freeze inside the pipe and could damage the flowmeter and block the solenoid valve. Once all air was removed from system, it is filled with nitrogen and flushed to clean every residual condensation inside. This part must be done carefully to not damage the flowmeter bearings. Then proceed the cool down of the system. For that purpose the tank is filled with liquid nitrogen, pressurized with 5 to 8 bar and the valve 
Investigation of internal flow of Cryogenic injection

for the injector is opened until the tank is empty again. This process takes about $10 \mathrm{~min}$. After that, the tank is filled again and the pressure is set up for the desired pressure. The acquisition data is turned on, and valve is opened, depending on the set mass flow rate, for the maximal of 150 seconds (until the tank is empty). A sample of the record of a test could be seen in Fig. 4

\section{Results and Discussion}

With the high speed camera two different flow regimes could be identified. The first one is the two phase flow regime (Fig. 5) which appears dark because the presence of a large number of bubbles and droplets and gaseous phases obscures the back light due to multiple scattering. The other one is the liquid phase regime (Fig. 6) which can be clearly characterized by its bright occurrence caused by the concentration of the light in the center due to refraction. These phenomena have been observed during the tests in injectors 1 and 2 . These phenomena occur after a long period of fluid flow and at high-pressure conditions (higher than 10 bars).

It is important to point out that even in this second flow regime (liquid flow), it is possible to see some bubbles in the pre-chamber of injectors. Bubbles were observed in all cases. These residual bubbles are generated in the pipe and are entrained into the flow going through the injector.

In Fig. 7] a group of bubbles undergoes an expansion inside the injector. Their characteristic length increases by almost a factor of two in the middle of injector due to the diminishing pressure along the injector. The resident time of this bubble in the tube of injector it is around 10-5 seconds and our pressure transducer is not able to measure the variation. But the presence of this bubble is a discontinuity in the flow and could generate instability.

Prior to the establishment of fully liquid flow regime, inside the injector a two-phase flow will be present (Fig. 8). For injector pressures higher than 15 bar the two-phase flow appear in the channel of injector and looks like the hydraulic flip described by Sou et al. (2008). Banuti e Hannemann (2010) suggest that this phenomenon could originate from heat transferred into the fluid from tube wall instead of cavitation. Accord to then, The heat transfer from wall, originate a density gradient that grows along of the channel length. So, instead a cavitation phenomenon (caused by pressure drop), and also due to the high sensitive of the cryogenic fluid with temperature or heat transfer, here we suppose the presence of the thermodynamic effect. Moreover, this is undistinguishable for the technic (shadowgraph) used in this research.

The presence of this two-phase flow could increase phenomenon like flashing in the jet or because of the presence of gas at high velocity, create chock waves around the jet (SIMOES-MOREIRA; BULLARD. 2003).

During the test, it was observed that the Jacob number is a good indication of the physical state of flow. Fig. 9 shows the evolution of Jacob number over time for the specific test in which a two-phase flow was observed almost during the entire test. Only at the end of the test, around $68 \mathrm{sec}$, the flow changes to a liquid phase flow and the Ja number approaches zero $(J a=0)$.

Considering the influence of temperature in the mass flow rate, it is possible to observe that the injectors 3 and 2 present (injector with conical and with tapered entrance) higher flow rate comparing to injector 1 (sharp entrance) as expected, because of the inflow conditions for different geometries. However, it is possible to see the flow rate increasing inversely proportional to the temperature. The saturation temperature are TS, and T/TS higher than 1 indicates a superheated liquid.

Table 2: Shows two results of the same injector for same temperature and different drop of pressure.

\begin{tabular}{ccc}
\hline $\begin{array}{c}\text { Mass flow } \\
(\mathbf{g} / \mathbf{s})\end{array}$ & $\begin{array}{c}\text { Drop pressure } \\
(\mathbf{b a r})\end{array}$ & $\begin{array}{c}\text { Temperature } \\
(\mathbf{K})\end{array}$ \\
\hline 13.5 & 2.75 & 91 \\
21.7 & 4.9 & 92 \\
\hline
\end{tabular}

Table 3: Shows the variation of the flow rate with the temperature.

\begin{tabular}{ccc}
\hline $\begin{array}{c}\text { Mass flow } \\
(\mathbf{g} / \mathbf{s})\end{array}$ & $\begin{array}{c}\text { Drop pressure } \\
(\mathbf{b a r})\end{array}$ & $\begin{array}{c}\text { Temperature } \\
(\mathbf{K})\end{array}$ \\
\hline 20.7 & 8.1 & 104 \\
31.1 & 8.2 & 98 \\
\hline
\end{tabular}

From the table, it can be seen that with the temperature decreasing from $104 \mathrm{~K}$ to $98 \mathrm{~K}$, almost of $5.7 \%$ change, the mass flow rate increasing from 20.7 to 31.1 $\mathrm{g} / \mathrm{s}$, approximately $35 \%$ difference. To have the same variation, it is necessary for a variation of $40 \%$ of the pressure (see tables 2 and 3). The liquid temperature are around the saturation temperature ( T/TS between 0.95 and 1). This means that as for the mass flow rate, the temperature conditions play a much more vital role than the pressure conditions, which require us the good 


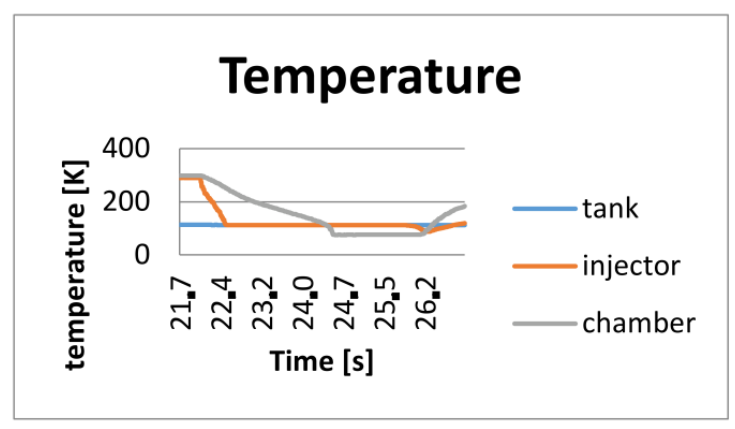

(a)

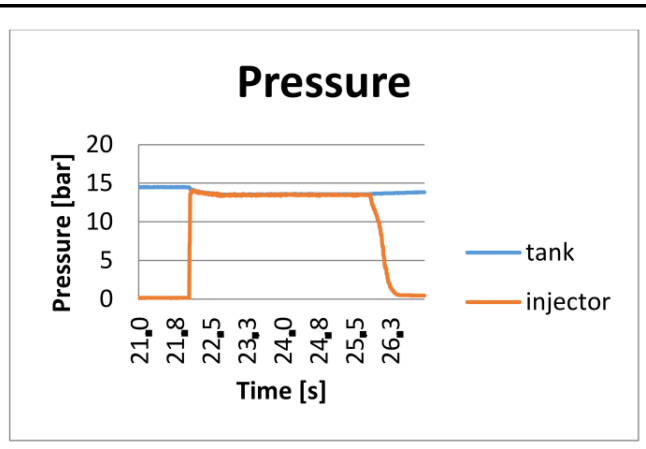

(b)

Figure 4: (a)Variation of injection temperature during the test (b) Variation of injection pressure during the test.

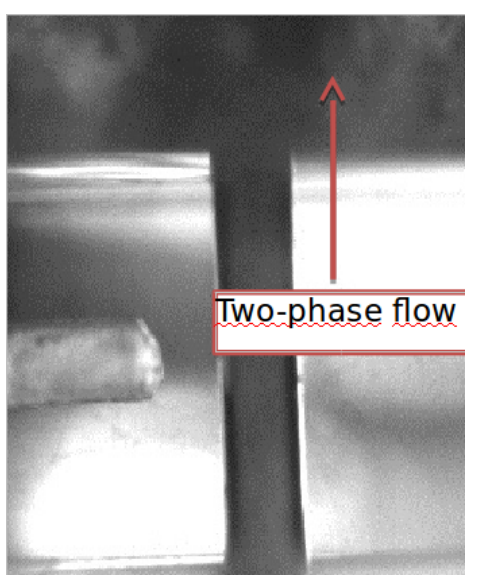

(a)

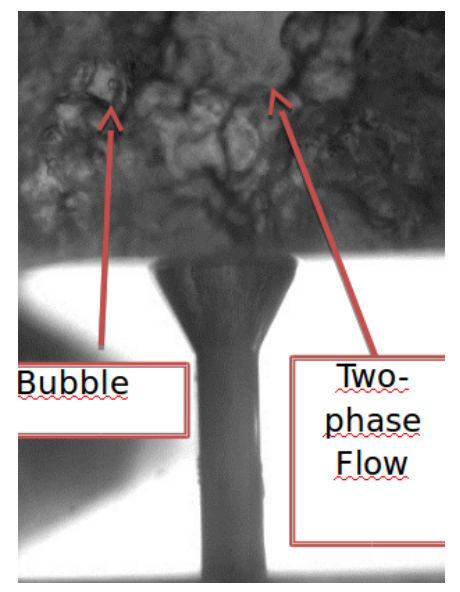

(b)

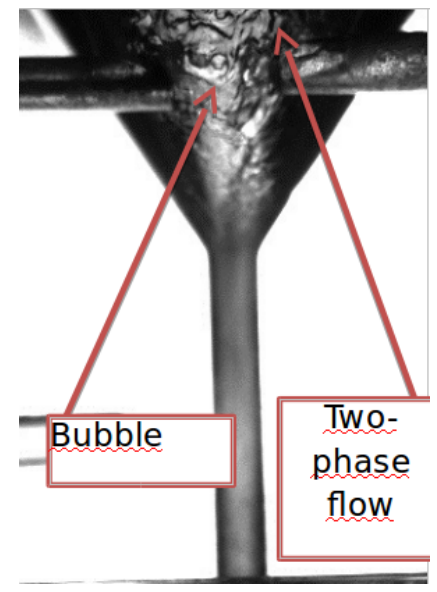

(c)

Figure 5: Two-phase flow inside the injectors, (a) injector 1, (b) Bubble and two phase flow inside the injector 2, (c) Bubble and two phase flow inside the injector 3 .

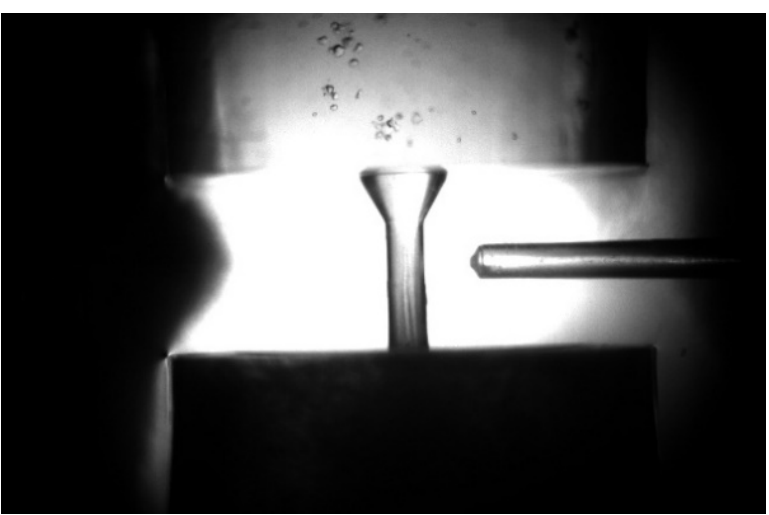

Figure 6: Bubble and liquid phase flow inside the injector 2. insulation of the cryogenic injection for the successive flashing study. The mass flow rate present an inversely proportional behavior to Jacob number (Fig. 10(a) explained by the fact that low $J a$ indicates less amount of gas dissolved in the flow, which leads to the higher density of the fluid.

The results indicate that the internal flow of cryogenic injectors has a great potential to influence the atomization process by presence of two-phase flow. The existence of a two-phase flow prior to the exit into the combustion chamber affects the mass flow rate and in addition may favor the onset of the flashing phenomenon which has a strong impact on the efficiency of an injector. The thermodynamic dependencies of flow prior injection must be considered in the project for initial 
Investigation of internal flow of Cryogenic injection

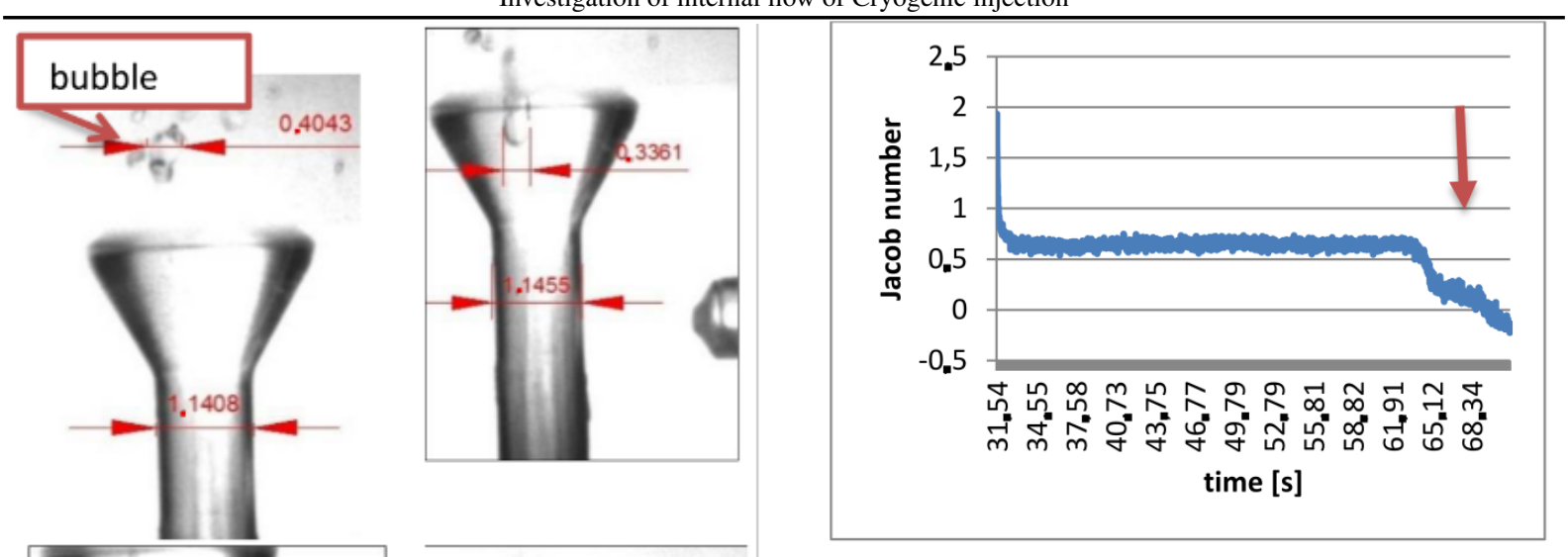

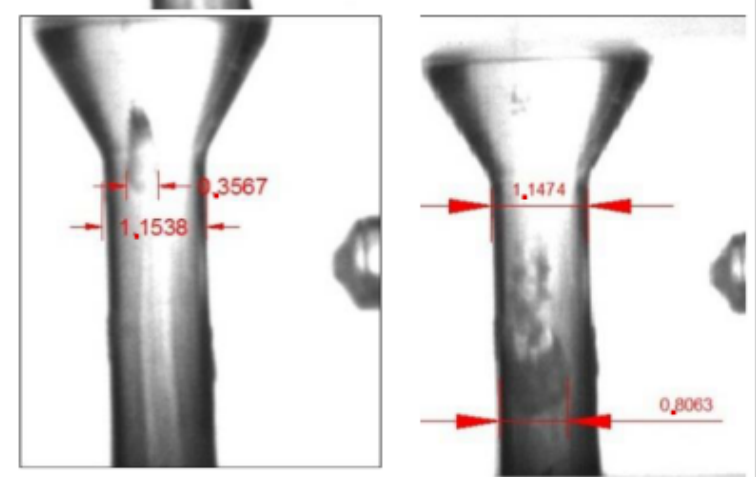

Figure 7: Expansion of the bubble through the injector.

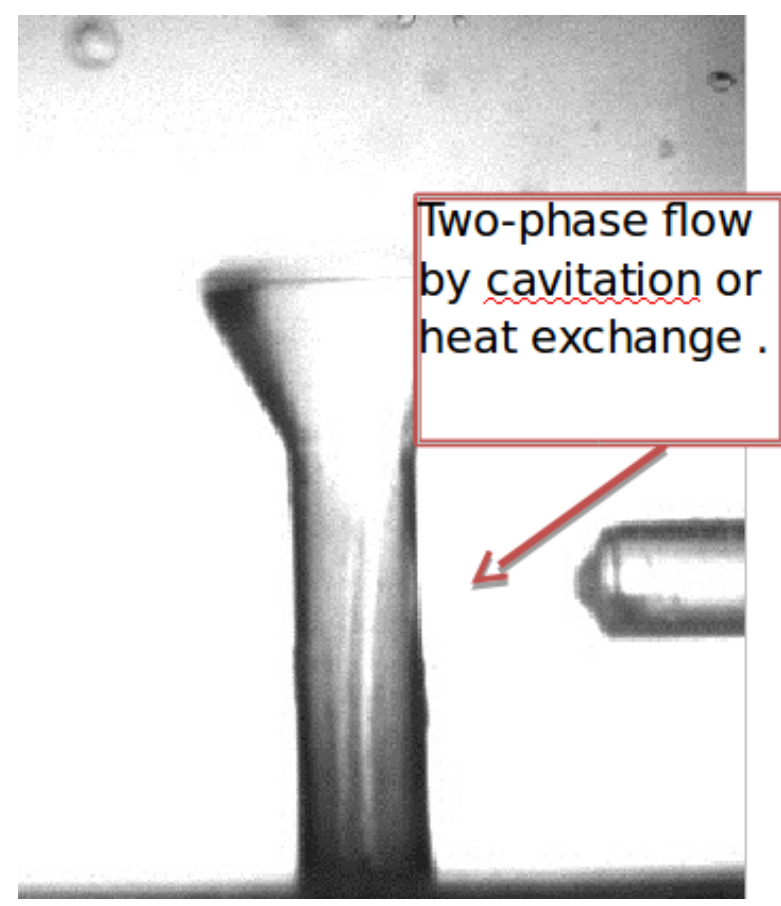

Figure 8: Cavitation or density gradient caused by wall heat transfer inside the injector 2 .
Figure 9: Test with change of phase. Variation of Jacob number. The red arrow indicates the phase change of the fluid.

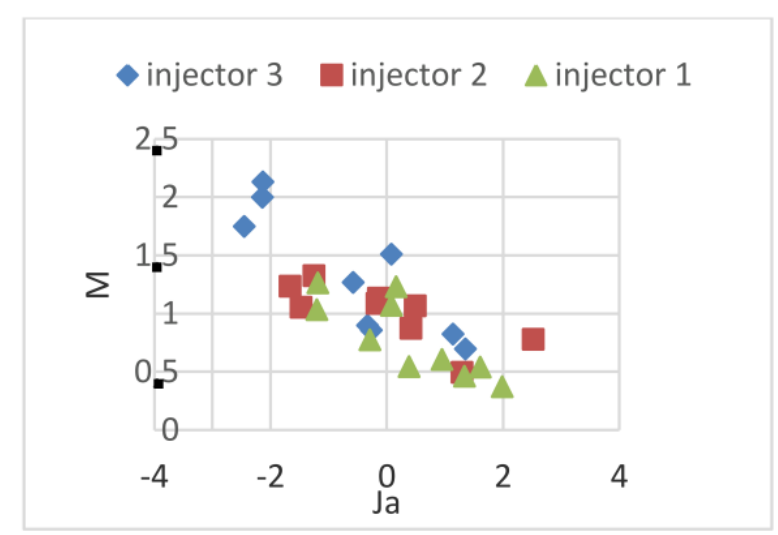

(a)

$\bullet$ injector $3 \square$ injector $2 \Delta$ injector 1

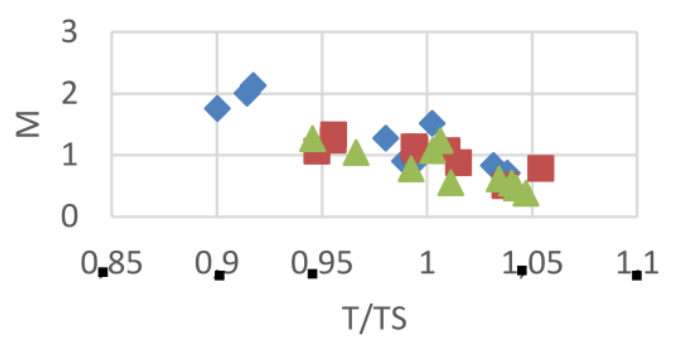

(b)

Figure 10: a) Variation of Mass flow rate with Ja b) Variation of mass flow rate with temperature. 
Investigation of internal flow of Cryogenic injection

conditions of a rocket engine.

\section{Conclusion}

In this research of internal flow of cryogenic jet , the flow inside jet injectors with cryogenic fluid is investigate with experimental methods. And the test facilities are carefully designed which allow the visualization and characterization of the flow. The mass flow rate presents a strong dependence with temperature (a $6 \%$ of variation on temperature create a $35 \%$ of variation in the flow rate). It was observed that the two-phase flow persists even with a long period of cooling down, but two regime of flow was observed. In the first regime, the two-phase flow are originated from pipelines because of chill-down phenomenon. The second one are originated in the injector's channel. The presence of two-phase flow could increase the phenomenon of flashing in the jet and the gas could originate shock waves around the jet. Two phenomenon could be responsible for the second regime, the cavitation and heat transfer from injector wall. The Jacob number shows good as an indicator of regime of flow. Residual bubble generated inside of the pipes go through the injector and expands. The bubbles's size grows up to almost double times and their presence could induce instabilities. The geometry of injector entrance affects the flow rate too, and the tapered injector presents higher flow rate than the sharp entrance injector. The results indicate that the internal flow of cryogenic injectors has a potential to interfere in the atomization and must be considered in the project for the engine design. The phenomenon observed in the work, as bubbles, and two-phase flow coming from pipes or generated in the injector channel it self, must be considered

\section{Acknowledgments}

The authors gratefully acknowledge the support from $\mathrm{CNPq}$ - Conselho Nacional de Desenvolvimento Científico e Tecnológico, of the Ministry for Science and Technology of Brazil and TUM- Technische Universität München.

\section{References}

BADOCK, C.; WIRTH, R.; FATH, A.; LEIPERTZ, A. Investigation of cavitation in real size diesel injection nozzles. International journal of heat and fluid flow, Elsevier, v. 20, n. 5, p. 538-544, 1999.
BANUTI, D.; HANNEMANN, K. Effect of injector wall heat flux on cryogenic injection. In: 46th AIAA/ASME/SAE/ASEE Joint Propulsion Conference \& Exhibit. Nashville, USA: [s.n.], 2010. p. 7139 .

Efficient multiphase rocket propellant injection model with high quality equation of state. In: Proceedings of the 4th Space Propulsion Conference. Cologne, Germany: [s.n.], 2014.

BRANAM, R.; TELAAR, J.; MAYER, W. Simulation of cryogenic jet injection, rcm 1. In: 2 International Workshop on Rocket Combustion Modeling. Lampoldshausen, Germany: [s.n.], 2001.

CHEHROUDI, B.; COHN, R.; TALLEY, D. Cryogenic shear layers: experiments and phenomenological modeling of the initial growth rate under subcritical and supercritical conditions. International Journal of Heat and Fluid Flow, Elsevier, v. 23, n. 5, p. 554-563, 2002.

CLEARY, V.; BOWEN, P.; WITLOX, H. Flashing liquid jets and two-phase droplet dispersion: I. experiments for derivation of droplet atomisation correlations. Journal of Hazardous Materials, Elsevier, v. 142, n. 3, p. 786-796, 2007.

De Giorgi, M. G.; FICARELLA, A.; TARANTINO, $M$. Evaluating cavitation regimes in an internal orifice at different temperatures using frequency analysis and visualization. International Journal of Heat and Fluid Flow, Elsevier, v. 39, n. 1, p. 160-172, 2013.

GAUTAM, V. Flow and atomization characteristics of cryogenic fluid from a coaxial rocket injector.

Tese (Doctor of Philosophy) - University of Maryland, College Park, 2007.

LIN, S. P.; REITZ, R. D. Drop and spray formation from a liquid jet. Annual review of fluid mechanics, Annual Reviews 4139 El Camino Way, PO Box 10139, Palo Alto, CA 94303-0139, USA, v. 30, n. 1, p. 85-105, 1998.

MAYER, W.; TAMURA, H. Propellant injection in a liquid oxygen/gaseous hydrogen rocket engine. Journal of Propulsion and Power, v. 12, n. 6, p. 1137-1147, 1996.

MAYER, W. O. H. Coaxial atomization of a round liquid jet in a high speed gas stream: a 
Investigation of internal flow of Cryogenic injection

phenomenological study. Experiments in Fluids, Springer, v. 16, n. 6, p. 401-410, 1994.

OSCHWALD, M.; SMITH, J.; BRANAM, R.; HUSSONG, J.; SCHIK, A.; CHEHROUDI, B.;

TALLEY, D. Injection of fluids into supercritical environments. Combustion Science and Technology, Taylor \& Francis, v. 178, n. 1-3, p. 49-100, 2006.

PAYRI, R.; SALVADOR, F.; GIMENO, J.; NOVELLA, $R$. Flow regime effects on non-cavitating injection nozzles over spray behavior. International Journal of Heat and Fluid Flow, Elsevier, v. 32, n. 1, p. 273-284, 2011.

RAMÉ, E.; HARTWIG, J. W.; MCQUILLEN, J. B. Flow visualization of liquid hydrogen line chill down tests. In: 52nd Aerospace Sciences Meeting. Maryland: [s.n.], 2014. p. 1074.

SHAEFFER, R.; HU, H.; CHUNG, J. An experimental study on liquid nitrogen pipe chilldown and heat transfer with pulse flows. International Journal of Heat and Mass Transfer, Elsevier, v. 67, n. 1, p. 955-966, 2013.

SHER, E.; BAR-KOHANY, T.; RASHKOVAN, A. Flash-boiling atomization. Progress in energy and combustion science, Elsevier, v. 34, n. 4, p. 417-439, 2008.

SIMOES-MOREIRA, J. R.; BULLARD, C. W. Pressure drop and flashing mechanisms in refrigerant expansion devices. International Journal of Refrigeration, Elsevier, v. 26, n. 7, p. 840-848, 2003.

SOU, A.; HOSOKAWA, S.; TOMIYAMA, A. Dimensionless numbers on cavitation in a nozzle of pressure atomizers. In: ICLASS. 11th Triennial International Annual Conference on Liquid Atomization and Spray Systems. Colorado USA, 2009.

SOU, A.; MAULANA, M. I.; ISOZAKI, K.; HOSOKAWA, S.; TOMIYAMA, A. Effects of nozzle geometry on cavitation in nozzles of pressure atomizers. Journal of Fluid Science and Technology, The Japan Society of Mechanical Engineers, v. 3, n. 5, p. 622-632, 2008.

VU, H.; AGUILAR, G. High-speed internal nozzle flow visualization of flashing jets. In: 11th Triennial International Annual Conference on Liquid
Atomization and Spray Systems. Colorado, USA: [s.n.], 2009.

YILDIZ, D.; RAMBAUD, P.; VANBEECK, J.; BUCHLIN, J.-M. A Study on the Dynamics of a Flashing Jet. Institute for Fluid Dynamics, 2002. 